the responsibility for asthma control on themselves and not their HCP (Table), even among those with average or poor symptom control. Many respondents believed that lack of asthma control was inevitable, with $81 \%$ accepting that they would experience symptoms and $86 \%$ acknowledging that asthma would have an impact on their life.

Conclusions Patients have low expectations of the level of asthma control that can be achieved. Despite a good relationship with their $\mathrm{HCP}$, many individuals do not attend regular asthma reviews, and awareness and use of Personal Asthma Action Plans is low. There is a clear need for continued education and initiatives to increase awareness among both HCPs and patients about asthma management plans and supported self-management.

Abstract P241 Table 1 Patient beliefs regarding the main responsibility for the management of their asthma

\begin{tabular}{lccc}
\hline & \multicolumn{2}{c}{ Level of perceived control } \\
\hline & $\begin{array}{c}\text { All patients } \\
(\mathbf{n}=\mathbf{1 0 8 3})\end{array}$ & $\begin{array}{c}\text { Very good or good } \\
(\mathbf{n = 8 5 9 )}\end{array}$ & $\begin{array}{c}\text { Average or poor } \\
(\mathbf{n}=\mathbf{2 2 4})\end{array}$ \\
\hline Responsibility & & & \\
Myself & $70 \%$ & $73 \%$ & $58 \%$ \\
Myself and HCP & $29 \%$ & $26 \%$ & $38 \%$ \\
HCP & $1 \%$ & $1 \%$ & $3 \%$ \\
\hline
\end{tabular}

$\mathrm{HCP}$, healthcare professional.

\section{P242 PATIENTS OVERESTIMATE THEIR DEGREE OF ASTHMA CONTROL DESPITE THE PRESENCE OF SYMPTOMS: A UK SURVEY}

doi:10.1136/thoraxinl-2012-202678.303

'M Fletcher, ${ }^{2} \mathrm{D}$ Hiles, ${ }^{1} \mathrm{E}$ Luck. ${ }^{1}$ Education for Health, Warwick, UK; ${ }^{2}$ Asthma UK, London, UK

Introduction and Objectives Many patients with asthma overestimate the extent to which their symptoms are controlled, which may suggest that the real-world burden of the disease is greater than reported. This abstract reports data from a UK-based survey assessing the variation between patients' perceptions of asthma control and their symptoms.

Methods This was a cross-sectional online survey administered by YouGov plc (November 2011) to a panel of over 350,000 individuals. Panellists who had previously identified themselves as having asthma were invited by e-mail to participate in the survey. Responses were collated and analysed by YouGov and Insight Research Group. Overall, 1083 individuals completed the survey; 49\% of respondents were aged over 55 years and $45 \%$ were male. Almost two-thirds (64\%) of patients were using both reliever and preventer therapy and $17 \%$ were using reliever medication only.

Results Most respondents reported that their asthma control was 'very good' (37\%) or 'good' (42\%). However, 19\% of respondents described having uncontrolled asthma (i.e. 'symptoms not very well managed') at least once a month and 10\% reported lack of asthma control at least once a week. In the 2 years prior to the survey, $12 \%$ of individuals had visited an accident-and-emergency department due to their asthma (ranging from 1 to 5 visits). Moreover, $41 \%$ of individuals used reliever medication at least once a day, and almost two-thirds experienced frequent (at least 'sometimes') day-time symptoms and over one-third had frequent night-time symptoms (Table). The most common day-time symptoms were coughing (experienced by $65 \%$ of individuals at least 'sometimes'), wheezing (62\%) and breathlessness (58\%). Despite this, 91\% of respondents were 'very satisfied' or 'fairly satisfied' (44\% and $47 \%$, respectively) with their level of asthma control, and $59 \%$ did not believe it was possible to improve control.

Conclusions Patients are generally satisfied with their level of asthma control despite evidence of poor symptom control, suggesting a disconnection between patient perception of asthma control and actual asthma control. This suggests a need for further education to help patients better recognize the symptoms of poor asthma control and how this can help them aspire to greater asthma control.

\section{P243 ARE HEALTHCARE PROFESSIONALS AWARE OF COSTS OF RESPIRATORY INHALERS?}

doi:10.1136/thoraxjnl-2012-202678.304

'V Mak, 'H Marlow, 'L Restrick, ${ }^{2} \mathrm{~A}$ Porter. 'London Respiratory Team, NHS London, London, England; ${ }^{2}$ NHS Improvement, Leicester, England

Introduction In 2011, 3 of the top 5 most expensive drugs to the NHS were respiratory inhalers, the most expensive being Seretide 250 evohaler. To achieve best value from our respiratory spend, healthcare professionals (HCPs) should know the relative costs of inhalers, and that their patients are using these devices appropriately. We undertook a survey of HCPs to test their knowledge of respiratory inhaler cost and how well the devices are used.

Methods We created a Survey Monkey questionnaire concerning the costs of commonly prescribed respiratory inhalers (see table) allowing respondents to click on an approximate range of costs for one month's treatment at normal recommended dose. We also asked about awareness of the evidence for effective use of metered dose inhalers (MDIs) by patients and HCPs. The survey was disseminated by email from various databases in community and hospital care within NHS London and beyond, especially to those involved in respiratory care.

Results There were 1274 respondents, 21\% were doctors, 38\% nurses, $21 \%$ pharmacists and $15 \%$ allied healthcare professionals (AHPs), 70\% had a respiratory interest and $89 \%$ were clinicians. Overall, the correct price range was identified by fewer than $50 \%$ of all respondents for the inhalers tested (except generic salbutamol), the worst being for Seretide 250 evohaler and Ventol in evohaler (see table). $76 \%$ of respondents were not aware that fewer than $10 \%$ of patients can use an MDI effectively and $87 \%$ were not aware that fewer than $10 \%$ of HCPs can demonstrate the correct use of an MDI. Having attended a London Respiratory Team (LRT) event significantly improved the correct response rate (see table).

Conclusions Most HCPs are not aware of the costs of inhalers and how poorly some inhalers are used. Increasing awareness of cost

Abstract P242 Table 1 Frequency of reliever medication use and asthma symptoms

\begin{tabular}{|c|c|c|c|c|c|c|c|}
\hline \multicolumn{8}{|l|}{ Use of reliever medication } \\
\hline & Never & $<1 /$ day & $1-2 /$ day & $3-4 /$ day & 5-6/day & & $7-8 /$ day \\
\hline$\%$ of respondents & $3 \%$ & $56 \%$ & $26 \%$ & $12 \%$ & $3 \%$ & & $1 \%$ \\
\hline \multicolumn{8}{|c|}{ Day-time and night-time asthma symptoms } \\
\hline & Never & Rarely & Sometimes & Often & & Everyday & \\
\hline Day-time, \% of respondents & $4 \%$ & $31 \%$ & $35 \%$ & $20 \%$ & & $10 \%$ & \\
\hline Night-time, $\%$ of respondents & $20 \%$ & $43 \%$ & $19 \%$ & $12 \%$ & & $6 \%$ & \\
\hline
\end{tabular}

